\title{
Estimating soil moisture using the Danish polarimetric SAR
}

\author{
Jiankang, Ji; Thomsen, A.; Skriver, Henning
}

Published in:

Proceedings of the International Geoscience and Remote Sensing Symposium

Link to article, DOI:

10.1109/IGARSS.1995.521103

Publication date:

1995

Document Version

Publisher's PDF, also known as Version of record

Link back to DTU Orbit

Citation (APA):

Jiankang, J., Thomsen, A., \& Skriver, H. (1995). Estimating soil moisture using the Danish polarimetric SAR. In Proceedings of the International Geoscience and Remote Sensing Symposium: Quantitative Remote Sensing for Science and Applications (Vol. Volume 2, pp. 942-944). IEEE. https://doi.org/10.1109/IGARSS.1995.521103

\section{General rights}

Copyright and moral rights for the publications made accessible in the public portal are retained by the authors and/or other copyright owners and it is a condition of accessing publications that users recognise and abide by the legal requirements associated with these rights.

- Users may download and print one copy of any publication from the public portal for the purpose of private study or research.

- You may not further distribute the material or use it for any profit-making activity or commercial gain

- You may freely distribute the URL identifying the publication in the public portal 


\title{
Estimating Soil Moisture Using the Danish Polarimetric SAR
}

\author{
Jiankang $\mathrm{Ji}^{1}$, Anton Thomsen ${ }^{2}$ and Henning Skriver ${ }^{1}$ \\ ${ }^{1}$ Danish Center for Remote Sensing, Electromagnetics Institute \\ Technical University of Denmark, Building 348, DK-2800 Lyngby, Denmark \\ Phone: +4545881444 Fax: +45 45931634 E-mail: jjk@emi.dtu.dk
}

${ }^{2}$ Danish Institute of Plant and Soil Sciences

Research Center Foulum, DK-8830 Tjele, Denmark

\begin{abstract}
The results of applying data from the Danish polarimetric SAR (EMISAR) to estimate soil moisture for bare fields have been presented. Fully calibrated C-band SAR images for $h \mathrm{~h}, \mathrm{vv}$ and cross polarizations have been used in this study. The measured surface roughness data showed that classical roughness autocorrelation functions (Gaussian and Exponential) were not able to fit natural surfaces well. A Gauss-Exp hybrid model which agreed better with the measured data has been proposed. Theoretical surface scattering models (POM, IEM), as well as an empirical model for retrieval of soil moisture and surface rms height [1] from co- and cross-polarized ratio, have been examined, but the results are less satisfactory. As soil moisture response to backscattering coefficient $\sigma^{\circ}$ is mainly coupled to surface roughness effect for bare fields. a bilinear model coupling volumetric soil moisture $m$, and surface rms height $\sigma$ to $\sigma^{\circ}$ has been applied. This model has previously been investigated with MAESTRO-1 data at Flevoland in The Netherlands [2]. The results from the present analysis showed that correlation coefficients between the model and the observed $\sigma^{\circ}$ are $0.86-0.81$ for hh, vv and hv (vh) polarizations. For estimation of surface parameters with the bilinear model, the correlation coefficient between the estimated and measured soil moisture, as well as rms height, is about 0.77. To improve the result, the local incidence angles need to be taken into account.
\end{abstract}

\section{INTRODUCTION}

Radar remote sensing has for many years showed great potentials for measurement of top layer soil moisture in large and small scales at all-weather conditions $[3,4]$. However, the soil moisture response to the backscattering coefficient $\sigma^{\circ}$ is influenced by vegetation and surface roughness effects, and the interaction among all three is not well understood. Lots of work has been done to model the relations among them. This paper presents some results on the estimation of soil moisture using data from the Danish polarimetric SAR acquired over an agricultural test site in Jutland, Denmark.

The Danish polarimetric SAR (EMISAR) is a result of a research and development project initiated in 1986 at the Electromagnetics Institute (EMI) of the Technical University of Denmark [5]. The SAR was first flown in 1989 and later a fully polarimetric system was developed, which has successfully acquired data since 1993 [6]. The polarimetric extensions of the system has been cosponsored by the EU's Joint Research Centre (JRC). An L-band system with full polarimetric capability was completed and tested early $1995[7]$ The EMISAR is used for scientific experiments conducted by the Danish Centre for Remote Sensing (DCRS) which was established early 1994 at EMI by the Danish National Research Foundation.

The SAR system is installed on a Danish Air Force Gulfstream aircraft, and it is normally operated from an altitude of approximately $13.000 \mathrm{~km}$, where the spatial resolution is 2 $\mathrm{m}$ by $2 \mathrm{~m}$, the ground range swath is approximately $12 \mathrm{~km}$ and typical angles of incidence angle range from 30 to 60 . The processed data from this system are fully calibrated by using an internal calibration system supplemented by optional external calibration targets. The cross polarisation contamination is generally suppressed by more than $30 \mathrm{~dB}$. The incidence angle for all the test fields is approximately 43 degrees, therefore incidence angle difference is ignored in the following analysis.

\section{EXPERIMENT DESCRIPTION}

One of the science projects conducted by DCRS is related to agricultural applications of multifrequency polarimetric SAR data including estimation of soil moisture. DCRS is collaborating with Research Center Foulum (RCF) on this project, and the data used in this paper were acquired at an agricultural test site at RCF in Jutland, Denmark, on April 28th. The test fields include a wheat field and two bare fields. The wheat plants at early growth stage are less than $10 \mathrm{~cm}$ in height and are sparse with green leaf area index (GLAI) of 0.16-0.19 $\left(\mathrm{cm}^{2} / \mathrm{cm}^{2}\right)$, therefore the vegetation effect can be neglected and the wheat field is treated as a bare one. One of the bare fields had three different scales of roughness produced with different types of rollers to test the roughness effect. The other bare field was partly irrigated in order to generate different degrees of water content for testing the soil moisture effect. Sampling lines in each test field were pre-determined according to water content and roughness variations. The top $0-5 \mathrm{~cm}$ and $0-10$ $\mathrm{cm}$ layer volumetric soil moisture were measured with TDR (Time Domain Reflectance) at every 25 meters (10 meters for the irrigated field) along sampling lines. The dielectric constant of soil was computed from soil moisture and soil texture data using an empirical model [8]. The soil surface roughness was measured by a self-made instrument which is a wooden board with a 2 -meter ruler attached. The surface height profile along the board is sampled at every $1 \mathrm{~cm}$ by measuring the vertical distance from the soil top to the edge of the horizontal board. Two or three roughness measurements were taken at each field and each measurement contained two sampling profiles - along and across flight direction. Climatological data and other ground truth data were also collected throughout the campaign period. The in-situ data collection was made in connection with the DANMAC-project (Danish Multisensor Airborne Campaign).

\section{GAUSS-EXP AUTOCORRELATION FUNCTION FOR SURFACE ROUGHNESS}

The surface roughness spectrum which is the Fourier transform of the autocorrelation function of the surface height, influences theoretical modelling of the backscattering coefficient. Usually, Gaussian or exponential functions are applied as the 
autocorrelation model for rough soil surface. Besides, others such as 1.5-power or two-scale models are also used [9]. However, these models were not able to describe the measured roughness data. The Gaussian model gave an overestimation in the region close to the origin and an underestimation at the tail, and vice versa for the exponential model. Other twoscale models have been examined too, but no good agreement was achieved. Therefore, a new hybrid autocorrelation function called the Gauss-Exp model has been investigated. It is the product of Gaussian and Exponential function:

$\rho(\xi)=\exp \left\{-\frac{1}{2}\left[\frac{\xi^{2}}{L^{2}}+\frac{|\xi|}{L}\right]\right\}$

where $\xi$ is the displacement and $L$ is the correlation length.

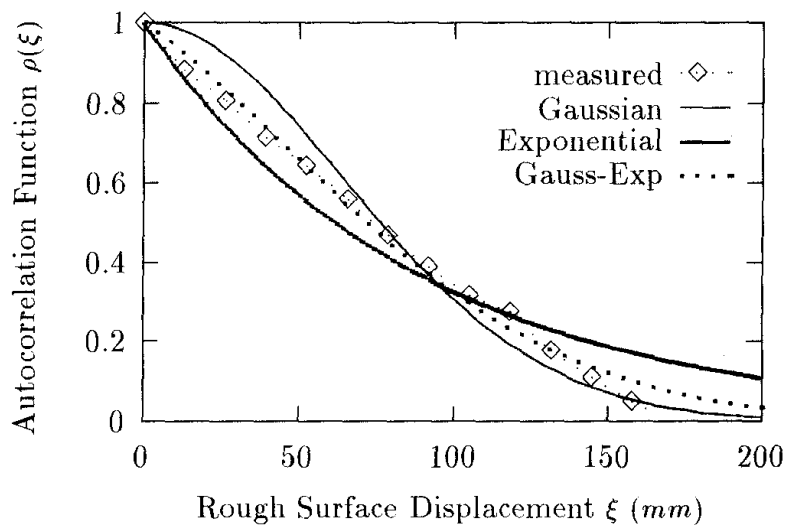

Figure 1: Comparisons between Gaussian, Exponential and Gauss-Exp autocorrelation function with measured roughness data.

This function is seen to be just between Gaussian and exponential model and agrees well with experimental data. Fig. 1 presents a typical correlation function measured and its correspondence with Gaussian, exponential and Gauss-Exp model. Another feature of (1) is that its $n t h$ power $\rho^{n}(\xi)$ has the same form as $\rho(\xi)$, which is convenient for theoretical calculation of the high-order roughness spectrum [9]. No closed form can be derived from the Fourier transform of (1), therefore a numerical approach has to be used to find the spectrum. The model has been tested with experimental data cited from [1] which were measured at the University of Michigan. Data were available for an incidence angle range from $20^{\circ}-60^{\circ}$. The soil surface of the test fields was well fitted with the Gauss-Exp correlation. Using the Integrated Equation Model (IEM) [9] it has been shown that theoretical results based on the Gauss-Exp model fitted the data better than those based on both the Gaussian and the exponential model.

\section{COMPARISON WITH THEORETICAL MODELS}

The evaluation of the applicability of classical scattering models to the SAR data has been made according to roughness scales. The measured roughness parameters extend from $k \sigma=0.27$ to $k \sigma=1.35$ and from $k l=5.85$ to $k l=15.22$ (where $k$ is the wave number, $\sigma$ is the rms height and $l$ is the correlation length). It is identified that the roughness conditions fall into the valid regions of the IEM and partly into the Physical Optical Model (POM), but outside the regions of the Small Perturbation Model (SPM) and Geometric Optical Model (GOM) [10]. Therefore, IEM and POM are applied in the theoretical evaluation.

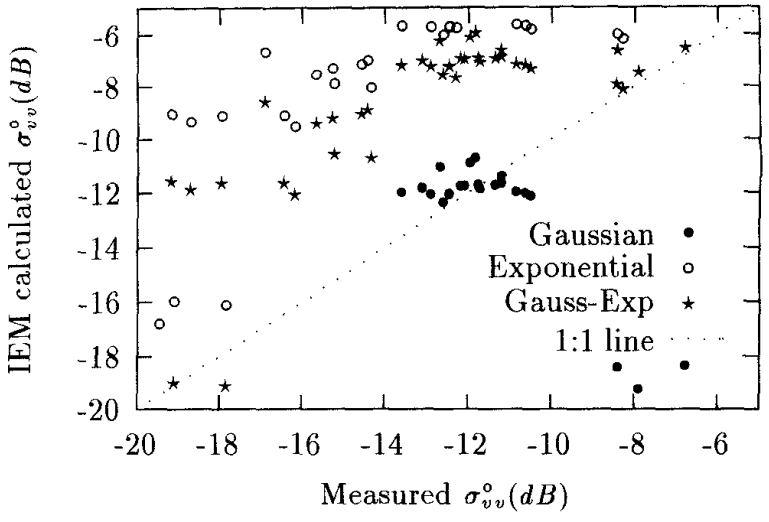

Figure 2: Comparisons of $\sigma^{\circ}$ between IEM and measured data.

Fig. 2 presents the result of the computed backscattering coefficient by IEM compared with the measured one. Gaussian, Exponential and Gauss-Exp correlation model are applied respectively. It is obvious that none of the three correlation models can give consistent agreement with the SAR data. Most of the computed values are larger than the SAR observed so that they are above the 1:1 line. It seems that Gaussian model is the best to some extent, but many computed points with this model are very small. The exponential model produces $\sigma^{\circ}$ about $6 d B$ higher than the observed. The Gauss-Exp model gives in general results about $4 d B$ larger than the SAR data. Similar results are obtained for the POM. Contrary to IEM, all the points for the POM are placed about $10 d B$ below the 1:1 line.

Thus, the conclusions from the comparison with theoretical solutions are: the observed SAR data disagree with IEM and POM predictions. The reason for this is probably an inaccurate correlation length $l$. Calculation shows that the variation of $\sigma^{\circ}$ with IEM and POM is sensitive to the variation of $k l$ as well as $k \sigma$. The simple instrument used for roughness measurement could give reliable value of $\sigma$ because of the large number of height samples taken; but the value of $l$ may be questionable because the $1 \mathrm{~cm}$ sampling interval is sparse for estimation of l. Another difficulty may be the periodical structure of natural soil surface. The surfaces along and across the row (planting) direction might show quite different correlation lengths. The $l$ used in the calculation is the mean value of $l$ at the along and across flight directions. Hence, the sensitivity of the model results on the correlation length will be studied in a future analysis, as well as the influence of the row direction effect.

For estimation of $m_{v}$ and $\sigma$, the empirical model for co- and cross-polarized ratio for rough surface [1] has also been examined with the observed data and the solution is unsatisfactory. The maximum correlation coefficient between the model predicted and the observed data is 0.5 .

\section{BILINEAR MODEL FOR $\sigma$ AND $m_{v}$}

The semi-empirical model developed by Ulaby et al. probably is the most simple and popular one used for soil moisture retrieval [10]. It is a linear correspondence between $\sigma^{\circ}$ and $m_{v}$. Roughness effects are implied in the coefficients of the model.

$\sigma_{\text {soil }}^{\circ}(d B)=A+B m_{v}$

where $A, B$ are constant coefficients related to roughness, incidence angle and polarization.

Based on the analysis of MAESTRO-1 SAR data [2], it is found that there is also a linear correspondence between $\sigma^{\circ}$ and 


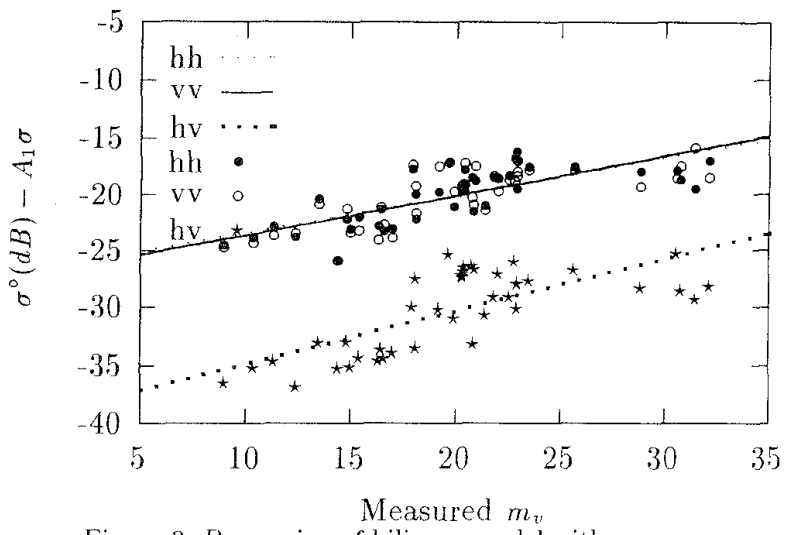

Figure 3: Regression of bilinear model with $m_{v}$.

rms height $\sigma$ under the assumption that moisture sensitivity $B$ has an eligible dependence on surface roughness. Therefore a bilinear model among $\sigma^{\circ}, \sigma$ and $m_{v}$ is investigated.

$\sigma_{\text {sonl }}^{\circ}(d B)=A_{0}+A_{1} \sigma+B m_{v}$

where $A_{0}, A_{1}, B$ are constant coefficients similar to (2).

Both (2) and (3) are examined with the present data set. The correlation coefficients $r$ between $\sigma^{\circ}$ and $m_{v}$ with (2) are about 0.65 , and with (3), $r$ increases to $0.84,0.86$ and 0.81 for $h \mathrm{~h}, \mathrm{vv}$ and $\mathrm{hv}$ polarizations, respectively. It illustrates that the linear correspondence (2) is modified by accounting for roughness effect. The positive values of the coefficients $A_{1}$ and $B$ show that larger roughness and moisture value result in stronger backscattering. Fig. 3 shows the variations of $\sigma_{\text {soil }}^{\circ}$ versus $m_{v}$ when roughness has been accounted for. The regressions of (3) for hh, $v v$ and hv polarizations are also shown in the figure.

\section{INVERSION}

In principle, estimation of soil moisture and rms height is possible from the matrix solutions of (3) with multipolarized SAR data. But large estimation errors result from using this algorithm because of the very high correlations between the hh and $v v$ channels. Other independent information is needed to distinguish the influence of $\sigma$ and $m_{v}$. If alyone of $\sigma$ and $m_{v}$ is known, the other can be inverted from (3) with SAR data. Previous studies show that $\sigma$ could be retrieved with multifrequency data $[11,12]$, or with multi-angle data [13]. For the present data set, suppose $\sigma$ is known, then soil moisture may be estimated from the regressions of (3) with multi-polarized SAR data. The resulting correlation coefficient between estimated and measured $m_{n}$ is 0.77 and the rms error is $4.5 \%$.

\section{CONCLUSIONS}

In this paper, EMISAR data have been applied to study the effects of soil moisture and surface roughness for bare fields. A hybrid Gauss-Exp autocorrelation function is investigated, which gives better agreement for natural soil surface. Classical models are applied to compute backscattering coefficient and some deviation is observed. Further analysis is needed to establish the sources of these deviations. A linear model for bare soil backscatter is used and modified as a bilinear relation by accounting for the roughness effect. The bilinear model is regressed with the observed data and good correlations are obtained. If the rms height could be evaluated, soil moisture could be estimated from (3).

To improve the results, the local incidence angle effect should be accounted for, as the test fields are not flat, local inclination angle at some of the sampling points could be as large as \pm 10 degrees.

\section{ACKNOWLEDGMENTS}

This work and data acquisitions have been sponsored by the Danish Space Board and the Danish National Research Foundation. Development of the EMISAR system has been co-sponsored by the Thomas B. Thriges Foundation, the Danish Technical Research Council (STVF), the Royal Danish Air Force, the Technical University of Denmark and the Joint Research Centre.

\section{REFERENCES}

[1] Yisok Oh, et al., 1992, An Empirical Model and An Inversion Technique for Radar Scattering from Bare Soil Surfaces, IEEE Trans. Geoscience and Remote Sensing, Vol. GE-30, No.2, pp. 370-381.

[2] J. Ji. H. Skriver, and P. Gudmandsen, 1994, Estimation of Soil Moisture from MAESTRO-1 SAR Data of Flevoland, Proceedings of EARSEL 14th Symposium, 8-10 June 1994, Chalmers University of Technology, Gothenborg, Sweden, pp. 103-110.

[3] M.C. Dobson, F.T. Ulaby, 1986, Active Microwave Soil Moisture Research, IEEE Trans. Geoscience and Remote Sensing, Vol. GE-24, No. 1, pp. 23-36.

[4] E.T. Engman, N. Chauhan, 1995, Status of Microwave Soil Moisture Measurements with Remote Sensing, Remote Sensing of Environment, Vol. 51, No. 1, pp. 189-198

[5] S.N. Madsen, E.L. Christensen, N. Skou, J. Dall, 1991, The Danish SAR System: Design and Initial Tests, IEEE Trans. Geoscience and Remote Sensing, Vol. GE-29, No. 3, pp. 417426 .

[6] E.L. Christensen, S.N. Madsen, J. Dall, N. Skou, K. Woelders, A. Netterstrøm, J. Granholm, and M. Dich, The Danish Polarimetric SAR for Remote Sensing Applications, Proc. IGARSS 1994. pp. 1361-1364.

[7] N. Skou, J. Granholm, K. Woelders, J. Rohde, J. Dall, and E.L. Christensen, A high Resolution Polarimetric L-Band SAR - Design and Test Results, this issue, 1995.

[8] M.C. Dobson, et al., 1984, A Reexamination of Soil Textural Effects on Microwave Emission and Backscattering, IEEE Trans. Geoscience and Remote Sensing, Vol. GE-22, No. 6, pp. $530-536$.

[9] A.K. Fung, 1994, Microwave Scattering and Emission Models and Their Applications, Artech House, Boston, pp. 120.

[10] F.T. Ulaby, et al., 1982, Microwave Remote Sensing: Active and Passive, Vol. 2, Addison. Wesly Publishing Company.

[11] T. Mo, J.R. Wang, T.J. Schmugge, 1988, Estimation of Surface Roughness Parameters from Dual-Frequency Measurements of Radar Backscattering Coefficients, IEEE Trans. Geoscience and Remote Sensing, Vol. GE-26, No. 5, pp. 574-579.

[12] K.S. Rao, S. Suresh, J.R. Wang, 1993, Estimation of Soil Moisture and Surface Roughness Parameters from Backscattering Coefficient, IEEE Trans. Geoscience and Remote Sensing, Vol. GE-31, No. 5, pp. 1094-1099.

[13] M. Autret, et al., 1989, Theoretical Study of The Sensitivity of the Microwave Backscattering Coefficient to Soil Surface Parameters, International Journal of Remote Sensing, Vol. 10, No. 1 , pp. 171-179. 